\title{
Exploring Self-Leadership Strategies and its Proposed use among Small and Medium Enterprise Leaders in Nigeria
}

\section{Enem Godwin Nnaemeka, Mohd Ashraff Mohd Anuar, Nor Wahiza Abdul} Wahat \& Ismi Arif Ismail

To Link this Article: http://dx.doi.org/10.6007/IJARBSS/v10-i11/8146

DOI:10.6007/IJARBSS/v10-i11/8146

Received: 25 September 2020, Revised: 23 October 2020, Accepted: 13 November 2020

Published Online: 30 November 2020

In-Text Citation: (Nnaemeka, Anuar, Abdul Wahat, \& Ismail, 2020)

To Cite this Article: Nnaemeka, E. G., Anuar, M. A. M., Abdul Wahat, N. W., \& Ismail, I. A. (2020). Exploring Self-Leadership Strategies and Its Proposed use among Small and Medium Enterprise Leaders in Nigeria. International Journal of Academic Research in Business and Social Sciences. 10(11), 821-838.

Copyright: (C) 2020 The Author(s)

Published by Human Resource Management Academic Research Society (www.hrmars.com)

This article is published under the Creative Commons Attribution (CC BY 4.0) license. Anyone may reproduce, distribute, translate and create derivative works of this article (for both commercial and non-commercial purposes), subject to full attribution to the original publication and authors. The full terms of this license may be seen at: http://creativecommons.org/licences/by/4.0/legalcode

Vol. 10, No. 11, 2020, Pg. 821 - 838

Full Terms \& Conditions of access and use can be found at http://hrmars.com/index.php/pages/detail/publication-ethics 


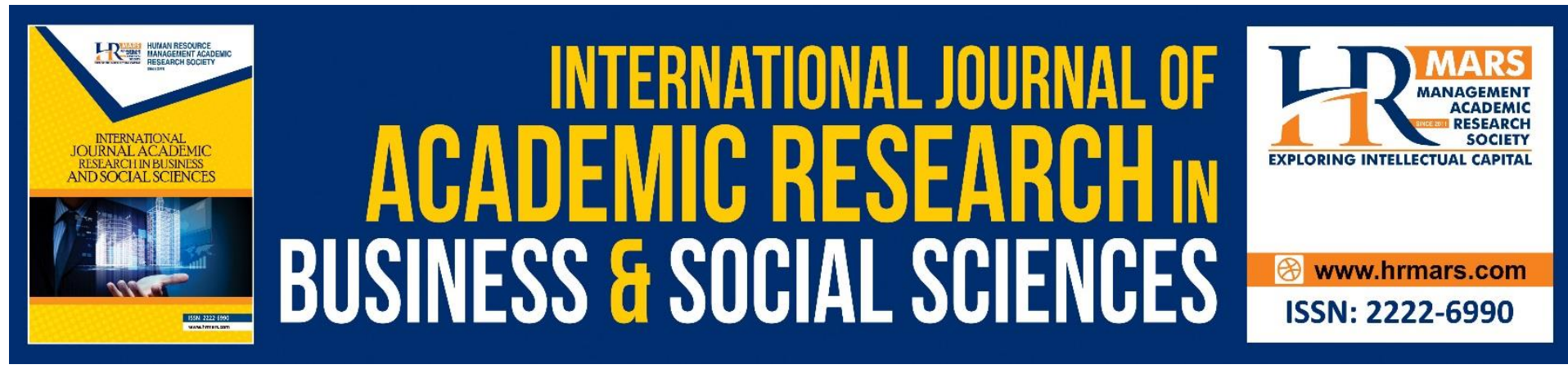

\title{
Exploring Self-Leadership Strategies and its Proposed use among Small and Medium Enterprise Leaders in Nigeria
}

\author{
Enem Godwin Nnaemeka, Mohd Ashraff Mohd Anuar, Nor \\ Wahiza Abdul Wahat \& Ismi Arif Ismail \\ Department of Professional Development and Continuing Education, Faculty of Educational \\ Studies, Universiti Putra Malaysia, Serdang, Selangor, Malaysia \\ Email: goddynnaemeka@gmail.com,mohdashraff@upm.edu.my,wahiza@upm.edu.my \& \\ ismi@upm.edu.my
}

\begin{abstract}
Self-leadership is a concept that aims to gain control on all aspect of life and individuals who practice self-leadership tend to improve on their performance. However, until recently the study of self-leadership has focused mainly on the personality of individuals, thereby neglecting the attitude of individuals and situational characteristics as crucial elements in selfleadership (Mutalib et al., 2013). This conceptual paper explores the self-leadership of small and medium enterprise (SME) leaders in Nigeria and investigates the crucial role the Nigeria business environment plays in the practice of self-leadership. The research methodology is qualitative descriptive research mainly relying on document analysis which constitutes an extensive review of relevant journals sourced from online platforms such as Google Scholars, Psycho.Net and from the researchers' institutions online resources. The ideal leadership for SME leaders has been a contentious issue in recent times; therefore in this paper attention is also drawn on the SME knowledge and experience of their self-leadership. The findings show that situational factors such as technology, poor infrastructure and government policy affect self-leadership among SMES leaders. The practical implications suggest that self-leadership has the potential for individual leadership development and could be a strategy to enhance personal effectiveness and organizational development. Additional Self-leadership development opportunities are also required because the emerging realities which indicate the increasing demand for less supervision in organizations, and individuals are expected to be independent with higher performance.
\end{abstract}

Keywords: Self-leadership, SMES, Business Environment, Nigeria, Situational Characteristics.

\section{Introduction}

Over the past 30 years, there have been great interests in the influence of self-leadership on organizational success both from practitioners (Further \& Rauthmann, 2013; Furtner et al., 2015) and academics (Politis, 2015; Neck \& Houghton, 2006). Consequently, organizations all over the world have spent quite a substantial amount annually, on self-leadership development initiatives aimed at improving leader performance and effectiveness (Ross, 
2015). Although the concept of self-leadership seems difficult to grasp because it is rarely taught in schools and people have to rely on self-help books, seminars and conference to learn about it However preliminary research into the concept shows that the practice of selfleadership has phenomenal positive effects (Manz, 2004, 1992; Prussia et al., 1998, Alves et al., 2006; Wang, Xie \& Cui, 2016). Manz (2015) stated that self-leadership can significantly increase individual productivity, health, efficacy, career success, self-esteem and personal well-being. Therefore the study of self-leadership has become increasingly popular within organizational behavior and so deserves considerable attention, especially this era of rapid changes in business environment with emphasis on reduced supervision cost and increased employee responsibilities.

One of the most important approaches of self-leadership suggests that individuals can influence their own behavior to act appropriately to achieve their set objective as long as they have the necessary skills and strategies (Manz and Houghton, 2004). Self-leadership is having a developed self-awareness and self-direction coupled with the ability to influence your communication, emotions and behaviors to perform a task (Browing, 2018; Houghton \& Neck, 2002; Manz \& Neck, 2004). Self-leadership includes cognitive and behavioral strategies through which individuals improve their performance. Sydänmaanlakka (2006) stated that self-leadership has three elements: sufficient self-confidence, good self-knowledge and the ability to reflect. Self-leadership is a lifelong process, where individuals can learn to lead bigger organization by first leading oneself (Sydänmaanlakka, 2006). They start by leading themselves, step by step, then teams, smaller units, before bigger entities. The purpose of this paper is to explore the essence of self-leadership strategies among small and medium enterprise (SME) in Nigeria

SME have become the engine room of an economy. The prosperity and the growth of modern economic system rely on the activities of SME. In Nigeria SME constitute about $97 \%$ of business enterprises (Oyeyinka, 2020) and contribute about 50\% of national GDP and hold about $70 \%$ of the industrial employment (Gumel 2019; Uchehara, 2017). However leadership of this enterprise has not been fully explored in management literature. One of the reasons being that human resource development (HRD) activities are predominantly carried out in larger organizations, consequently, an important HRD function such as leadership is ignored in SME sector (Voca \& Havolli, 2019) In Nigeria particularly leadership research in SMEs literature has been scares. Okeke (2019) stated that SME owners in Nigeria lack in-depth knowledge of the leadership style they operate. Hence it becomes imperative to evaluate the long term implications of such leadership styles on their performance and growth of the enterprise in a challenging business environment such as Nigeria. Similarly Uchehara, (2017) observed that poor leadership, financial constraint and infrastructural obstacles are some of the major challenges preventing the enterprise in Nigeria from actualizing their potentials, As a result of these outcomes, the traditional leadership paradigms of which they establish their style seem to lose its relevance. Moreover self-leadership has been studied extensively (e.g. Maykrantz and Houghton, 2018; Alves et al., 2006). However there is still little knowledge of it in the context of SME (Ziyae \& Heydari, 2016) and therefore SME knowledge and experience of self-leadership is rather limited, particularly within the Nigeria context where such study is non-existent.

Self-leadership is argued to be effective on a number of workplace beneficial outcomes including job satisfaction (Sesen et al., 2017; Shad et al., 2015) organizational performance (Geldenhuys et al., 2014; Konradtet et al., 2009) and employee commitment (Park, 2008: Neck \& Houghton 2006). However self-leadership is still an under-researched topic despite its 
growing popularity and potential benefits. Previous researches on self-leadership have focused on personal characteristics and attitudes of individuals who practice self-leadership (Van Zyl, E., 2014), while neglecting the influence of environmental factors. Only one study by Mutalib et al., (2013) discussed the influence of situational characteristics on self-leadership. According to the authors, situational characteristics can affect the extent to which individual dispositions and attitudes of individuals who practice self-leadership can be effective. This is because situational factors and individual characteristics influence individual behaviors (Conard \& Matthews, 2008) a viewpoint known as "interactionism' (Meyer, Dalal \& Bonaccio 2009). Situational characteristics have been found to be important in the understanding of self-leadership (Neck \& Houghton, 2006) because individuals can act differently when the environment is changed (Mutalib et al., 2013).

The purpose of this paper therefore was to explore the use of self-leadership strategies among SME in Nigeria and how the SME leaders can utilize the strategies of self-leadership to overcome the stressful business environment in which they transact their business. It will also highlight the influence of environmental factors on the trait and behaviors of SME leaders, a perspective that has not been given adequate attention as one of the determinants of selfleadership (Mutalib et al., 2013). This paper will be useful in understanding the SME knowledge and experience of self-leadership within the Nigeria context. Also from a theoretical perspective this paper highlights the important of self-leadership by employing the most relevant self-leadership theories. The points raised in this paper are relevant to Human resource development because self-leadership increases individual self-confidence and self-esteem which may improve productivity and workplace outcome. In addition individuals will be self-motivated by the knowledge gained from internalizing the selfleadership strategies and become more effective in leading oneself before leading others.

\section{Methodology}

The research method for this paper was qualitative descriptive design; qualitative research methodology is the most appropriate for this type of study because it explores and proposes the use of self-leadership among SME leaders in Nigeria. The research on the concept of selfleadership in Nigeria is non-existent and to explore this phenomenon, the researcher described in-depth the construct of self-leadership to help in the understanding of the knowledge of self-leadership among SME leaders in Nigeria. This supports the assertion by Herbert et al., (2017) that the purpose of qualitative research lies in its ability to comprehensively explain a poorly understood phenomenon or of events to enable easy comprehension of experiences. The scarcity of data on self-leadership in Nigeria therefore informed the choice of qualitative research for this paper.

Data for this paper was gathered by sourcing journal articles and scientific books both subscribed and free resources which is in line with the purpose of the research, to describe and analyze in-depth the construct of self-leadership to enable a better understanding of the concept in the context of SME business in Nigeria. A total of 30 journal articles were reviewed, articles were sourced from the researchers institution database such as; Scopus, Wiley Online, Springer Link, Sage, Procedia and Emerald Insight. Other online resources include Google Scholars and Psycho.Net. Content analysis method was used to analyze these articles which assisted in literature review and to align with the objective and scope of this research. This is in line with what Gopaldas, (2016) stated, that data collection and data analysis technique is qualitative research characterized by the use of visual and textual materials, diaries, 
observation and immersion, as well as interviews. To narrow the search, key words were used along Boolean Operators.

\section{Definition and Origin of Self-leadership}

Self-leadership is defined as a self-influencing processes through which individuals control their behavior to achieve self-direction and self-motivation necessary to perform (Neck \& Houghton, 2006; Neck, \& Singh, 2004). It involves influences individuals exert over themselves to achieve a higher level of performance and effectiveness (Amundsen \& Martinsen, 2015). Self-leadership increases individual effectiveness an intrinsic motivation and other psychological well-being such as autonomy, environmental mastery, proactive, health and physical well-being. Self-leadership is a self-influencing process whereby behavioral-oriented management process and that of intrinsic motivation are related to individual self-control (Manz \& Sims, 2001; Manz, 2015). Self-leadership is about individuals who take initiates and set goals and utilize their potential abilities of human resources to achieve their objectives (Browning, 2018; Brown \& Ryan, 2013). Self-leadership incorporates a set of behavioral and cognitive strategies by which individuals control their behaviors and influence themselves to achieve desirable behavior and outcome (Carmeli et al. 2006; Ho and Nesbit 2014).

Self-leadership origin is traced to Manz (1986) after his seminal work titled 'Toward an expanded theory of self-influence processes in organizations" was published in the Academy of Management Review. Self-leadership is closely related to Self-management (Manz and Sims, 2001). However it differentiates the level of self-influence and to involve wider spectrum of behavioral concept to internally established standards beyond that of selfmanagement which focuses on regulating compliances from external standards (Stewart et al., 2011). Self-management emphasizes on 'how' to accomplish a task and meet external standards whereas self-leadership focuses on 'what' (setting of standard and objective) and 'why' (analyzing current situation) should be accomplished (O'Dwyer, 2014). Self-leadership is rooted in Bandura's social cognitive theory (Bandura, 1986) self-control theory, (Cautela, 1969; Neck \& Houghton, 2006) self-regulatory theory (Carver and Scheier, 1981; Houghton \& Neck, 2002) and intrinsic motivation (Ryan \& Deci, 2019; Ryan \& Deci, 2000).

The introduction of self-leadership challenges the traditional leadership archetypes which focus on how leaders or supervisors influence their subordinates (Shek et al, 2015). Stewart et al., (2011) stated that self-leadership as an alternative viewpoint in organizational psychology and the traditional leadership was initially intended to guide subordinates in the organization to be self-motivated and self-directed towards achieving organizational performance (Pearce \& Manz, 2011). However changes, expertise and the increasing expansion in size of the organization, indicate that leaders do not possess all the answers to the numerous problems in the organization, so organizations realize that they need the creative energy and knowledge of every employee. Subordinates therefore are encouraged to take initiatives and lead themselves to better performance (Stewart et al., 2011; Shek et al, 2015; Sesen \& Tabak, 2016). Self-leadership is also conceptualized as a normative model which means it is prescriptive in nature and offers normative advice and emphasizes on how things should be done as against descriptive theory or deductive theory which seeks to explain. Therefore self-leadership prescribes behavioral and cognitive strategies which are divided into three categories; behavioral focused strategies, natural reward strategies and cognitive thought pattern strategies (Neck \& Houghton, 2006; Houghton and Yoho, 2005). Each of these self-leadership strategies is explained in the next section. 


\section{Behavioral Focused Strategies}

Behavioral focused strategies are about behavioral regulatory processes which often result to behavioral change. It involves self-awareness concepts through which individuals manage their own behaviors and also encourages individuals to initiate behaviors that are desirable for better performance while discarding those behaviors that are antagonistic to performance. The strategies adopted are; self-observation, self-goal setting, self-rewards selfdiscipline (self-correction feedback) and self-cueing (Manz \& Neck 2004; Ward and Eagle, 2018). The first strategy is self-observation, which implies how individuals become aware of when, and why and under what condition can one observe a behavior necessary to perform (Alves et al., 2016). The underlying purpose here is to know when to adopt a desirable behavior for optimal performance and also when to eliminate non desirable behavior. By instinct so many people practice this strategy without realizing they are practicing it.

The second strategy is self-goal setting which according to Neck et al., (2017) provides direction for self-leadership. This strategy implies that individual set goals which they aspire to accomplish, because this strategy will motivate the individual to work hard as well as evaluate their performance towards achieving their set goals. In addition it leads the individual to self-assessment about setting goals that are not only challenging but must be achievable and realistic, both long term goals and day to day goals. The third strategy is selfreward; this process involves identifying and creating mental and physical incentives toward achieving the desired goals (Manz 2015). Once the individual has identified the rewarding object, he/she rewards himself and engages in self-praise after the completion of the task. The fourth strategy is the self-discipline or self-punishment (recently termed as self-corrective feedback by Neck \& Houghton, 2006). This strategy is self-evaluation and making sure only desirable behaviors are promoted. It involves identifying all behaviors that have to do with guilt or destructive behaviors and eliminates them and replaces them with desirable behaviors (Neck \& Houghton, 2006; Bailey et al., 2016). The fifth and final strategy is selfcueing which involves using reminders and positive cues to remind oneself about important task while eliminating negative cues from non-important tasks (Manz, 2015).

\section{Natural Reward Strategies}

Natural reward strategies focus on positively identifying with the task by establishing motivating situation. This is done by incorporating enjoyable features in the processes and activities in the course of performing the task (Houghton et al. 2004). According Manz \& Neck, (2004), this strategy is rooted in self-determination theory as well as increase intrinsic motivation (Deci \& Ryan, 1985). Natural reward strategies are useful when dealing with tasks that are not motivating, but which must be done, therefore the individual includes some features which will make him enjoy the task. This enables the person focus on the positive aspect of the task as a source of motivation rather than focusing on the negative aspect. There are two dimensions of Natural reward strategies; the first involves incorporating features of natural reward in the task and the second involves focusing on natural reward inherent in the task (Neck \& Manz, 2013; Furtner et al., 2015). This will give the individual the feeling of selfcontrol and competence because when individuals are in a position to determine what happens around them, they have a feeling of self-control (Deci \& Ryan 2000) and when the individual enjoys his/her job and then enhances it by incorporating some enjoyable features, it leads to increase performance which gives the person a sense of competence (Manz \& Neck 2004). 


\section{Constructive Thought Pattern Strategies}

Constructive thought pattern strategies involve establishing and controlling thought processes by discarding negative beliefs and assumptions. It implies that individuals can alter their thought processes in a desirable way with positive thinking which will improve their performance (Politis 2015). The process involves identifying and modifying dysfunctional thought and replacing them with rational thoughts. Constructive thought pattern strategy is sometimes referred to as Thought self-leadership and it makes use of visualization as mental technique used to visualize successful future performance. (Ekmekçi, 2017). The underlying principles in constructive thought pattern strategies is to promote positive self-image and self-talk while eliminating negative self-image, self-talk, dysfunctional beliefs and assumptions. There are three steps in constructive thought pattern strategies; (1), identifying dysfunctional beliefs and assumption and eliminating them. (2), promoting and engaging in positive self-talk. (3), visualization of successful future performance (Marques-Quinteiro, et al., 2018).

The first step is to evaluate beliefs and assumption, then identify and eliminate those ones that are dysfunctional after which it must be replaced with rational thoughts to avoid reoccurrence of the dysfunctional thought process (Manjurul, 2019). This is done by challenging those beliefs and analyzing and altering one's mental script which is individuals past experience in life and then replace them with rational thoughts. According to Burns (1980) there are eleven primary categories of dysfunctional thinking which includes; (1) extreme thinking (2) all-or-nothing thinking, (3) over-generalization, (4) mental filter, (5) disqualifying the positive, (6) jumping to conclusion (mind reading and fortune telling), (7) magnifying and minimizing, (8) emotional reasoning, (9) should statement, (10) labeling and mislabeling, and (11) personalization. After identifying all these, individuals then replace them with positive thoughts. The second step is to constantly engage in positive self-talk, this refers to the dialogue or self-talk that goes on within oneself which can happen silently or aloud (Marques-Quinteiro, et al., 2018). Self-talk reinforces confidence and helps motivate an individual into maintaining the right behavior and higher performance. Evidence in sports psychology suggests that athletes who engage in positive self-talk had successful performance (Megheirkouni, 2018; Neck \& Manz, 1992) and in clinical psychology those who engage in positive affirmation or self-talk quit from negative life style such as alcoholism and smoking (Neck \& Manz, 1992). The third dimension is visualization of successful performance which implies the creation of mental imagery and seeing in ones mind's eye how events pan out even before they occur. Evidence in research also indicates that sales people who use visualization have reported increase in sales performance. (Panagopoulos \& Ogilve, 2015). The combination of these three dimension of the constructive thought pattern strategies will enable an individual create a pattern of behavior that will increase individual confidence, motivation and overall performance. In this paper the authors used social cognitive theory (Bandura, 1986), and self-determination theory (Deci \& Ryan 1985) to analyze self-leadership strategies in the context of SME leadership in Nigeria, the theories are discussed in the next section

\section{Social Cognitive Theory}

Social cognitive theory (Bandura, 1986), which evolved from social learning theory, proposes a model of triadic reciprocal causation in which personal factors, environmental factors and cognitive factors have a mutual interactive effect of reciprocal determinism among them. In other words, human behavior is formed due to the continuous interaction between personal 
factors, behavioral factors, and environmental factors (Ozmete and Hira, 2011). According to Bandura (1986) personal factors include; cognitive, effective and biological events such as behavioral judgmental and self-regulatory influences while behavioral factors include behavioral patterns such as specific behavioral activity patterns linked to an individual and environmental factors include social influences such as family, work environment, and other broad social network of influences that affect feelings and behavior. Though there is no fixed pattern whereby the reciprocal interactions occur, these three factors operate as mutual determinants on one another depending on the situation, activities and sociocultural constrains (Bussey \& Bandura, 1999).

The theory also postulates that individuals can control their own performance standard (Bandura, 1986). Individual knowledge and actions are influenced by their ability and the outcome of their efforts, so people can regulate their behaviors, plan their actions to attain higher performance. The theory further explains that individuals learn by observing, imitating and modeling their behavior from people they regard as models. According to Middleton et al., (2018) individual beliefs, values and goals describes how they imitate actions from other people in situations of learning which explains the behavior. The theory states that individuals have the ability to alter their thoughts and think positively or negatively depending on their past experiences especially when presented with similar situations (Bandura, 2001). Therefore, the way people think determines their actions and subsequently the behavior they adopt. They have the ability to alter their behaviors by controlling their thoughts, actions and feelings through self-reflection.

Social cognitive theory promotes the concept of self-efficacy and considers it as means by which individuals can increase their confidence through the acquisition of skills and knowledge. Self-efficacy is the belief individuals have about their ability to effectively preform a particular task (Bandura, 2001). Stewart et al., (2011) stressed that self-efficacy is a key construct of social cognitive theory as well as very important to self-leadership because it leads to individual self-assessment and increase in confidence about their capability to perform a task and it is a major objective of natural reward and constructive though pattern strategies. Therefore social cognitive theory is related to self-leadership strategies of natural reward and constructive thought pattern strategies through the enhancement of self-efficacy, which increases the self-confidence of individual to perform a task at a higher level. In addition social cognitive theory emphasizes that self-regulatory system is a process which involves self-monitoring, self-judgments and self-reactions and these elements comprises the basic principles of self-leadership behavioral focus strategies of self-observation and selfdiscipline which enable individuals manage their own behaviors and initiate behavioral standard that are desirable for better performance.

\section{Self-Determination Theory}

Self-Determination theory is a theory of motivation which focuses on the importance of the growth individuals makes through their behavioral self-regulation and personality development (Deci \& Ryan, 2000a). The theory states that there are three basic psychological needs which must be fulfilled to adapt effectively for increased personal well-being and social development. These needs are; autonomy, competence and relatedness. Autonomy refers to the freedom and the self-governance individuals exercise in order to control and influence events surrounding their lives (Yun et al., 2006). Competence on the other hand refers to the need to achieve growth, mastery and expertise in ones chosen field and the quest to test ones skills on challenging task by exploring the environment whereas relatedness refers to the 
need for individuals to integrate in the society by being member of a group, association with people and communion with others (Van den Broeck et al., 2010).

The theory also consists of influences of intrinsic and extrinsic motivation (Deci and Ryan, 1985). Intrinsic motivation is built internally and comes from within an individual while extrinsic motivation comes from external factors dealing with expectations of rewards and the avoidance punishment. The theory of intrinsic motivation states that motivation comes internally from an individual whereby he/she autonomously engage in activities which are enjoyable and leads to attainment of a particular goal (Deci et al., 2017). Extrinsic motivation on the hand refers to external motivation where an individual performs an activity to attain a separate outcome based on external factors such as physical reward. For instance, when employee engages in learning new skills for the pleasure of mastering an additional skill set and when an employee learns a new skill for the purpose of career advancement and promotion. Intrinsic motivation enables individuals to fulfill an innate psychological need and exhibit self-determined behavior on matters that interest them and for self-satisfaction (Deci \& Ryan, 1985; Sweet et al., 2012).

Ryan and Deci, (2019) observed that self-determination is a need theory; therefore, individuals have the capacity to influence their own action to actualize their goals through engaging actively in matters that are of concern to them. According to the authors, the individual actualizes this through contextual support or through evolves inner resources. They argue that the individual's prior developmental support for autonomy or competence enables them to be self-determined before the manifestation of intrinsic motivation. Self-leadership is built on intrinsic motivation especially the strategies of natural reward. This is because individuals most often are tasked to complete a difficult job which they might not enjoy doing or which they are not competent at doing, hence intrinsic motivation then enables them to complete a task which often are not enjoyable but must be done. Therefore selfdetermination theory is related to self-leadership because it is the fundamental mechanism that promotes intrinsic motivation and intrinsic motivation on the other hand is the central explanatory factor of self-leadership strategies especially natural reward and behavioral focused strategies, because it concerns an approach to problem resolution, higher positive feelings, job satisfaction, creativity and innovation and performance (Neck \& Houghton, 2006; Curral and Marques-Quinteiro, 2009; Carmeli et al. 2006).

\section{Small and Medium Size Enterprise (SME) in Nigeria}

The definition and classification of SME varies among nations of the world. These definitions often reflect the economic and socio-cultural difference of these nations and are inclined towards investment capital, number of staff, turn over, or a combination of investment capital and number of staff (Robu, 2013). In Nigeria Small and Medium Enterprise Development Agency (SMEDAN), the body responsible for coordinating the development of SME classifies them based on two factors; the number of employees and working capital. The agency also categorizes them into micro, small and medium enterprise (MSME). In Nigeria SMEDAN characterises SME based on the three criteria below 
Table 1. SMEDAN classification of MSME

\begin{tabular}{|l|l|l|l|}
\hline & Size and Category & Employment & $\begin{array}{l}\text { Assets (N Million) excluding } \\
\text { (land \& buildings), }\end{array}$ \\
\hline 1. & Micro Enterprise & Below 10 & Less than 5 million \\
\hline 2. & Small Enterprise & $10-49$ & From 5 million to 50million \\
\hline 3. & Medium Enterprise & $50-199$ & From 50 million to 500 million \\
\hline
\end{tabular}

SMEDAN policy on MSME (2013).

However, based on the national perspective on taxonomy these classifications on employment and assets do not include land and building (SMEDAN, 2013). Another definition from Central Bank of Nigeria (CBN) in 2005 describes SME as an enterprise with 200 thousand naira as their assets base without any specific number of staff. These assets based criterion of definition employed by SMEDAN and CBN has a lot of demerits because they can be periodically altered due to inflation and therefore could be misrepresented (Etuk et al., 2014). Oyeyinka (2020) stated that almost $97 \%$ of businesses operating in Nigeria can be referred to as small and medium scale enterprise and their activities could be found in all sectors of the economy but are predominately involved in wholesale and retail trade. SME in Nigeria are distributed in clusters within the six geographic regions such as the Oshogbo \& Abeokuta Tie and Dye SME clusters and the Lagos Otigba ICT both located in the south west region. Others include the Nnewi Automotive SME cluster and the Aba leather \& Fashion SME cluster in the south East region and finally the Kano Leather SME cluster in the North West. Okafor et al., (2018) stated that these businesses represent $90 \%$ of wholesale and retail trade despite coming from the manufacturing and industrial sector as regards the number of enterprise.

These SME have the potential to contribute to the growth and development of the country if given the necessary support and an enabling environment by the government to make meaningful contribution to the economy. However, the enterprise is plagued by harsh economic conditions which have made it difficult for business to grow within the Nigeria business environment. Numerous among such harsh conditions include financial constraint, poor state of infrastructural facilities, difficulty in accessing government loans, lack of managerial and leadership skills. These factors can also be grouped into internal and external factors; the internal factors include: difficulties in sourcing raw material, inadequate working capital, low capacity utilization, stiff competition from larger companies, lack of management strategies and poor educational background of SME owners while the external factors include; those related to capital shortage, taxation and regulations, product liability patent and franchising abuses. Others are policy inconsistencies, multiple taxation, harsh regulatory requirements and trade (Ifekwem \& Ademola, 2016).

In addition to all these factors, Etuk et al., (2014) observed that lack of entrepreneur skills constitutes a major problem and conflict between SME and entrepreneur; this is because so many small businesses in Nigeria remain small due to lack of knowledge and skills in managing their business beyond the subsistence level and therefore they lack innovation and global competitiveness. Though SME in Nigeria is confronted with numerous challenges there are also enormous potential in all of the sectors waiting to be tapped. Oyeyinka, (2020) noted that there are growing opportunities in some sectors for expansion and profit which include entertainment and leisure, Low Tech agro-processing industry like cassava, oil palm and other oil with strong indication for export. According to the author, high tech clusters such as Lagos ICT has enormous potential for expansion and employment generation. Other areas of ICT such as telecom and biotechnology (agriculture and health) are also viable options for 
economic growth. Given the strategic importance of SME to the Nigeria polity, and the idea of reviewing existing policies and implementation framework, the need arises for an alternative form of leadership such as self-leadership which will enhance individual leadership effectiveness and create independent individual with a developed self-direction and selfinfluence.

\section{Self-leadership Development in Nigeria SME}

Self-leadership development is built on the premise that work motivation can be achieved through the amount of personal efforts and resourced allocated towards work role and through self-regulatory mechanism for direction, intensity and persistent behaviors (Marques-Quinteiro, 2009) Though there is a general consensus that self-leadership can be developed but it requires a supportive environment, adequate policy implementation framework and organizational resources to succeed (O'Dwyer, 2014). SME in Nigeria requires individual who are willing to take initiative, set priorities and solve problem. This paper proposes that self-leadership would allow for individual self-mastery and persistent through increased self-awareness, proactive behavior, emotional intelligence, self-motivation and innovation needed to navigate challenges inherent in a stressful business environment such as Nigeria. Although these characteristics have been regularly linked with self-leadership none has tried to discuss it in relation a stressful business environment. We will now discuss briefly on how these characteristics are connected to SME self-leadership development in Nigeria

\section{Self-awareness and Proactive Behavior}

Self-leadership begins with individual self-awareness, a clear and accurate understanding requirement of the need to change, improve and enhance one's abilities (O'Dwyer, 2014). Developing self-awareness as a leader will strengthen one's personality and lead to individual effectiveness and organizational success. When SME leaders develop self-awareness and conscientiousness it will increase performance and their willingness to remain persistent. Locke, (2005) stated that self-awareness leaders have an excellent knowledge of their own cognitive ability and their leadership skills. They manage their strengths and weaknesses in order to optimize their leadership. Self-awareness leaders stay focused and have clear understanding of their environment and know when they need to adjust their behavior to suit the changing environment. This is very important because situations in Nigeria change very often and SME leaders should be prepared to take advantage. The constructive though pattern strategy of self-leadership conceptualized from cognitive therapy increases individual self-awareness and enables the individual to control and modify their thought process and replacing dysfunctional thoughts with rational thoughts (Neck \& Manz, 1996). In addition, proactive behavior implies efforts initiated by individual to bring about changes to oneself and to the environment (Parker et al., 2006). Fuller and Marler (2009) stated in their metaanalysis that leaders with proactive behavior have excellent career success and high job performance. Proactive behavior is also part of behavior focused strategies of self-leadership which encourages individuals to initiate behaviors that are desirable for better performance.

\section{Emotional Intelligence and Stressful Environment}

There are so many definitions of emotional intelligence; however, the concept focuses on the ability of an individual to recognize one's emotions and those of others to assist in managing one's relationships, thoughts and decision making (Zyl et al., 2017). Goleman, (1998) observed 
that working in a stressful environment is linked to variety of issues such as reduced communication, decreased efficiency, quality problem and errors. SME leaders should develop their emotional intelligence issues in the environment will lead to so many errors and interruptions. For instance the epileptic power supply is enough to beat the patience of any SME leader whose job depends solely on power supply. Therefore developing their emotional intelligence will enable them exercise lots patience and think towards other alternative power supply. Individuals handle stress different in their own way but emotional intelligence will enable them respond appropriately to stress. Self-leadership is positively associated with emotional Intelligence (Baker, 2018; Alabdulbaqi et al., 2019). Self-goal setting and selfobservation are found to be present in El. Self-observation results in behavioral change and implies how individuals become aware of when and why and under what condition can one observe a behavior necessary to perform (Alves et al., 2016). Through behavioral change an individual can make adjustment to control their emotions, and cope with stressful environment, understand other people's emotions and build relationship. People who are high in El have a coping mechanism to stress because they direct their emotions towards constructive activities which enable them absorb the negative effects the eternal environment maybe throwing at them. Therefore, self-leadership help an individual learn about emotional intelligence which helps regulate one's emotion and in relation with others and the environment.

\section{Self-leadership and Innovation}

Self-leadership has a great influence on employee innovative behavior (Carmeli et al., 2006). Many researchers on self-leadership have endorsed the idea that self-leadership strategies affect individual and team innovative behavior and also help to achieve organizational success (Ward \& Eagle, 2018; Manz and Neck, 2004; Houghton and Neck, 2006). Organizations not only want to survive; they also want to sustain their performance for a long period of time. And one of the ways of improving and sustaining performance is through innovation Individuals who practice self-leadership enjoy certain level of autonomy which enables them to come up with novel ideas and become creative in their workplace. Innovation is critical in a competitive environment and every organization must innovate in order to stay alive. SME leaders in Nigeria must innovate in order to overcome some of the challenges the environment poses to them. In this era of rapid economic changes, they must incorporate technology into their business, such as embracing information technology and learning digital computer. Self-leadership strategies will give them the leverage to do all that as this will increase their capacity to innovate. Self-leadership plays a crucial role in innovation and business performance in any organization (Browning, 2018). Self-leadership focuses on being autonomous, competitive and proactive, and through this people learn to focus on issues that matter, and with freedom of less supervision adopt various creative ideas that lead to innovation. Therefore, self-leadership is vital in any organization, and more importantly organizations that need constant innovation as a means of survival.

\section{Self-leadership and Self-motivation}

Self-motivation is the gathering of all inner resources, energy and direction of behavior towards achieving a desire goal. It is the ability to stay focused, motivated and become enthusiastic about one's own goal (Di Domenico \& Ryan, 2017). Self-leadership practice affects individual cognitive and behavioral tendencies and through this process individuals maintain their motivation. The constructive thought pattern strategies are related to 
motivation because of the use of self-talk, visualization and belief system. These strategies make it possible for an individual to be internally motivated. The management of though patterns ensure individual effectiveness in self-leadership. An individual may decide to think positively or negatively when presented with certain challenges. If he thinks positively out of 'curiosity instinct' and beliefs he might turn those challenges as an opportunity for growth and performance, however if he thinks negatively the 'flight instinct' sets in and out of fear of new things might withdraw and therefore miss an opportunity for growth. Self-leadership is a cognitive-based motivational process that acts as a mechanism to influence the direction, intensity, and persistence of behaviour towards achieving work effectiveness(Mutalib et al., 2013). Self-leadership strategies will increase SME leader's self-confidence and self-esteem and they will improve on their self-motivation and through their individual competence and autonomy will improve on their performance. Therefore, self-leadership enables individual to maintain motivation level in a harsh economic environment.

\section{Discussions}

Self-leadership is important among leaders of today especially in the context of SME because it helps them to stay focus in running their business. In Nigeria SME leaders play a vital role in supporting and motivating the employees to take initiative and become responsible in their work roles. Though these SME leaders are inclined to learning and adopting of self-leadership as their ideal style of leadership, they still have little knowledge about the concept. However some SME leaders in Nigeria have used their inherent self-leadership skills to overcome some of the challenges without being aware of self-leadership strategies. The most important reason for this outcome is their sheer individual determination to succeed supported only by personal factors. In order words this personal factor is driven by their innate selfdetermination to achieve their personal goals and the intrinsic motivation that is embedded in self-determination theory which regulates their behavior for a long term successful business operations.

In this paper it is shown that the main reasons some SME leaders navigate the murky waters of Nigeria business environment is that they show more significant effect of self-motivation which is one of the key self-regulatory mechanisms of self-determination theory in their everyday activities. It is from self-motivation which implies the gathering of inner resources involving energy, spirituality, ability to stay focus and motivation which makes it possible for other characteristics such as emotional intelligence, proactive behavior, and innovation to be achieved. By being self-driven SME leaders can become aware of their own thought patterns, and behaviors, and they can challenge false assumptions and become self-directed and minimize external influences. The world is witnessing unprecedented changes in the way businesses are transacted and leaders and subordinates are becoming more self-directed hence they learn to concentrate on long term goals and plan ahead to achieve their aims. SME leaders and entrepreneurs are champions of economic developments (Sathe, 2003). In Nigeria where micro businesses are abound the leaders are capable of growing from contemporary enterprises to larger corporation by learning to lead themselves first before leading others. Self-leadership creates a balance in people because; oneself; is the most difficult person to lead, and once an individual masters himself it will be easier to lead others. Moreover, due to the rapidly changing business environment managers are now training as self-leaders, therefore managers of the future will be grounded in self-leadership skills and ushers in new era of enhanced sensitivity and conscientiousness. SME leaders in Nigeria should be prepared to effectively internalize the strategies of self-leadership without which 
the practice of self-leadership will be difficult to actualize. Internalization of these strategies will increase their self-knowledge, self-confidence and the practice of self-leadership in order to take advantage of the changing business environment. Sydänmaanlakka (2005) opined that leaders of the future will be versatile learners with high self-esteem and self-knowledge who can succeed in challenging situations. When reflecting on the lack of self-leadership skills of SME leaders in Nigeria business environment one could notice exposures to numerous external impulses which could beat their mental and psychological state. These affect them to a large extent that they become confused and disoriented and eventually their business goes into extinct and moribund. Without self-leadership it would be difficult to control ones mental and emotional well-being.

It is also important to note that in this paper SME leaders have a managerial role to play in terms of motivating their subordinates. As self-leaders their subordinates model their lifestyle towards them. They observe and imitate their leaders which they consider as models. In order wards, their values, beliefs and goals must reflect those of their leaders for them to learn selfleadership strategies. In addition SME leaders should motivate their subordinates in work context to promote innovation and creativity. In this instance self-leaders could serve as motivational mechanism through which their subordinates can internalize self-leadership strategies. And reach their individual objectives. Lin (2017) observed that team managers can lead team members to focus on reaching individual aspirations, ideals, and ambitions. Using self-leadership skills leaders can inspire self-confidence of subordinates and their potential to create will increase.

\section{Conclusion}

This paper set out to explore self-leadership strategies among SME in Nigeria and how SME leaders can utilize self-leadership strategies to overcome the challenges of the stressful business environment in which they transact their business. It also highlights implications of environmental factors such as poor infrastructural facilities, policy inconsistences and technology on the trait and behaviors of SME leaders. These factors are some of the features of stressful environment of and they are largely responsible for the failed business operations in Nigeria. The findings also show that the experience, knowledge and the practice of selfleadership strategies among SME in Nigeria is limited and studies of self-leadership in the country is non-existent. Findings indicate that self-leadership is not a popular concept in African countries. From the 30 articles reviewed only 12 of them; (Katewa \& Heystek, 2019; Katewa, 2016; Rambe and Modise, 2016; Van Zyl, 2011, 2013, 2015, Mahembe et al., 2013; Jooste, 2014, Jooste et al., 2014; Bimray and Jooste, 2014, Debby and Rahschulte, 2018; Harunavamwe, 2020) involved studies conducted within the Southern African region only and none to the researchers knowledge has been conducted in other regions.

Therefore this study will be the first of its kind conducted with the Nigeria context. This paper also goes beyond existing research as it tries to define a more comprehensive theory of selfleadership by gathering relevant self-leadership theories. It is also important to note that there is no unified theory of self-leadership however in this paper social cognitive theory (Bandura, 1986) and self-determination theory (Deci and Ryan, 1985) was used as the underlying support for learning and adoption of self-leadership strategies. The theories emphasized on self-reflection and self-regulation as unique human capabilities which can be used to alter one's behavior and cognition for individual effectiveness and higher performance. The paper also advances the study of self-leadership that investigates the influence of situational characteristics such as harsh business environment on behavior and 
personality of those who practice self-leadership, until recently only a single study (Mutalib et al., 2013), has examined the effect of situational characteristics such as perceived stressful environment, job autonomy and workload as they affect self-leadership. This paper recommends that future research should be conducted on this theoretical proposition to look into the effects of situational characteristics as determinant of self-leadership to get some empirical data and elaborate on these findings.

\section{References}

Alabdulbaqi, E., Banjar, H., and Felemban. (2019). The Relationship between Self-Leadership and Emotional Intelligence among Staff Nurses. IOSR Journal of Nursing and Health Science (IOSR-JNHS). ISSN: 2320-1940 Volume 8, Issue 1 Ver. III. (Jan. - Feb .2019), PP 58-65. www.iosrjournals.org

Amundsen, S., \& Martinsen, O. L. (2015). Linking Empowering Leadership to Job Satisfaction, Work Effort, and Creativity: The Role of Self-Leadership and Psychological Empowerment. Journal of Leadership \& Organizational Studies, 22(3), 304-323. https://doi.org/10.1177/1548051814565819.

Bailey, S. F., Barber, L. K., \& Justice, L. M. (2016). Is self-leadership just self-regulation? Exploring construct validity with HEXACO and self-regulatory traits. Current Psychology, 37(1), 149-161. doi:10.1007/s12144-016-9498

Baker, C. (2018). A Study of Emotional Intelligence and Self Leadership. SAM Advanced Management Journal. 82. 18-28.

Bandura, A. (2001). 'Social cognitive theory: An agentic perspective', Annual Review Psychology, vol. 52, pp. 1-26.

Bandura, A. (1986). Social foundations of thought and action: A social cognitive theory. Englewood Cliffs, NJ: Prentice-Hall.

Beck, A. (1970). Cognitive Therapy: Nature and Relation to Behavior Therapy. Behavior Therapy, 1, 184-200. http://dx.doi.org/10.1016/S0005-7894(70)80030-2

Browning, M. (2018). Self-Leadership: Why It Matters. International Journal of Business and Social Science Volume 9, Number 2, p.p. 14-18.

Cautela, J. R. (1969). Behavioral therapy and self-control: Techniques and applications. In C. M. Franks (Ed.), Behavioral therapy: appraisal and status (pp. 323-340). NY: McGrawHill.

Deci, E. L., \& Ryan, R. M. (2000). The "What" and "Why" of Goal Pursuits: Human Needs and the Self-Determination of Behavior. Psychological Inquiry, 11(4), 227-268.

Deci, E. L., \& Ryan, R. M. (2011), 'Self-determination theory', Handbook of Theories of Social Psychology 1, 416-433.

Deci, E. L., \& Ryan, R. M. (1985). Intrinsic motivation and self-determination in human behaviour. New York: Plenum.

Deci, E. L., Olafsen, A. H., \& Ryan, R. M. (2017). Self-determination theory in work organizations: The state of a science. Annual Review of Organizational Psychology and Organizational Behavior, 4, 19-43. doi: 10.1146/annurev-orgpsych-032516-113108.

Di Domenico, S. I., and Ryan, R. M. (2017). The Emerging Neuroscience of Intrinsic Motivation: A New Frontier in Self-Determination Research. Journal Frontiers in Human Neuroscience volume 11.

https://www.frontiersin.org/article/10.3389/fnhum.2017.00145, DOI 10.3389/fnhum.2017.00145. ISSN 1662-5161 
Geldenhuys, M., Laba, K., \& Venter, C. (2014). Meaningful work, work engagement and organisational commitment. South African Journal of Industrial Psychology. 40. 1. 10.4102/sajip. v40i1.1098.

Goleman, D. (1998) "What Makes a Leader," Harvard Business Review, vol. 76, p. 93-102

Ho, J., \& Nesbit, P. L. (2014). Self-leadership in a Chinese context: Work outcomes and the moderating role of job autonomy. Group \& Organization Management, 39(4), 389415.

Houghton, J. D., \& Neck, C. P. (2002), 'The revised self-leadership questionnaire', Journal of Managerial Psychology, vol. 17, no. 8, p. 672.

Houghton, J. D., \& Yoho, S. K. (2005). Toward a Contingency Model of Leadership and Psychological Empowerment: When Should Self-Leadership Be Encouraged? Journal of Leadership \&amp; Organizational Studies, 11(4), 65-83.

Ifekwem, N., \& Ademola, O. (2016). Survival strategies and sustainability of small and medium enterprises in the Oshodi-Isolo local government area of Lagos State. Acta University Sapientiae, Economics and Business, 4(1), 103-118. doi:10.1515/auseb-2016-0006.

Konradt, U., Andreßen, P., \& Ellwart, T. (2009) Self-leadership in organizational teams: A multilevel analysis of moderators and mediators, European Journal of Work and Organizational Psychology, 18:3, 322-346, DOI: 10.1080/13594320701693225.

Manz, C. C., \& Neck, C. P. (2004). Mastering Self-Leadership: Empowering Yourself for Personal Excellence (3rd ed.). Pearson Prentice-Hall, Upper Saddle River, NJ.

Manz, C. C. (1986). Self-leadership: Toward an expanded theory of self-influence processes in organizations. Academy of Management Review, 11.3, 585-600.

Manz, C. C. (2015). Taking the self-leadership high road: Smooth surface or potholes ahead? The Academy of Management perspectives: 29(1), 132-151

Manz, C. C., Skaggs, B. C., Pearce, C. L., and Wassenaar, C. L., (2015). Serving one another: Are shared and self-leadership the keys to service sustainability? Journal of Organizational Behavior, J. Organize. behavior. 36, 607-612 (2015) Published online 25 January 2015 in Wiley Online Library (wileyonlinelibrary.com) DOI: 10.1002/job.1991.

Manz, C. C., \& Neck, C. P. (2004). Mastering Self-Leadership: Empowering Yourselffor Personal Excellence (2nd ed.). Upper Saddle River: Prentice Hall.

Manz, C. C., \& Sims, H. P. 1991. Super Leadership: Beyond the myth of heroic leadership. Organizational Dynamics, 19(4): 18-35.

Manz, C. C., \& Sims, H. P. (2001). The new super leadership: Leading others to lead themselves. Berrett-Koehler Publishers.

Marques-Quinteiro, P., Vargas, R., Eifler, N., \& C., L. (2018). Employee adaptive performance and job satisfaction during organizational crisis: the role of self-leadership. European Journal of Work and Organizational Psychology. 1-16. 10.1080/1359432X.2018.1551882.

Maykrantz, S., \& Houghton, J. (2018). Self-leadership and stress among college students: Examining the moderating role of coping skills. Journal of American College Health. 68. 10.1080/07448481.2018.1515759.

Megheirkouni, M. (2018). Leadership and Decision-Making Styles in Large-Scale Sporting Events. Event Management. 22. 785-801. 10.3727/152599518X15299559876162.

Meyer, R. D., Dalal, R. S., \& Bonaccio, S. (2009), 'A meta-analytic investigation into the moderating effects of situational strength on the conscientiousness-performance relationship', Journal of Organizational Behaviour, vol. 30, pp. 1077-1102. 
Middleton, L., Hall, H., \& Raeside, R. (2019). Applications and applicability of Social Cognitive Theory in information science research. Journal of Librarianship and Information Science, 51(4), 927-937. https://doi.org/10.1177/0961000618769985

Mutalib, S. K. (2013). Towards a theory of self-leadership and individual characteristics: understanding the impact of situational factors.

Neck, C. P., \& Manz, C.C (1996). 'Thought self-leadership: The impact of mental strategies training on employee cognition, behavior, and affect', Journal of Organizational Behavior, vol. 17, no. 5, pp. 445-467.

Neck, C. P., \& Manz, C. C. (1992). Thought self-leadership: The influence of self- talk and mental imagery on performance. Journal of Organizational Behavior, 13(7), 681-699.

Neck, C. P., Manz, C. C., \& Houghton, J. D. (2017). Self-leadership: The definitive guide to personal excellence. Los Angeles: SAGE

Neck, C., \& Houghton, J. (2006). Two decades of self-leadership theory and research: Past developments, present trends, and future possibilities. Journal of Managerial Psychology, 21: 270-295.

Neck, C. P., \& Manz, C. C. (2013). Mastering self-leadership: empowering yourself for personal excellence (6th ed.). Upper Saddle River, NJ: Pearson.

O'Dwyer, T. F. (2014). Consequences of self-leadership in an Irish public sector knowledge organization.

Ozmete, E., \& Hira, T. (2011). Conceptual analysis of behavioral theories/models: Application to financial behavior. European Journal of Social Sciences, 18(3), 386-404.

Oyeyinka, B. O., (2020). Financial System Strategy 2020 FSS 2020 International Conference. SME Issues, Challenges and Prospects. https://www.cbn.gov.ng

Parker, S. K., Williams, H., \& Turner, N. (2006). Modeling the antecedents of proactive behaviour at work. Journal of Applied Psychology, 91, 636-652.

Panagopoulos, N., \& Ogilvie, J. (2015). Can salespeople lead themselves? Thought selfleadership strategies and their influence on sales performance. Industrial Marketing Management, 47, 190-203

Pearce, C. L., \& Manz, C. C. (2011). Leadership Centrality and Corporate Social Ir-Responsibility (CSIR): The Potential Ameliorating Effects of Self and Shared Leadership on CSIR. Journal of Business Ethics, 102(4), 563-579

Politis, J. (2015). Entrepreneurial Orientation, Creativity and Productivity: The Influence of Self-leadershipStrategies. Management Studies, 3(7-8), 203-213. https://doi.org/10.17265/2328-2185/2015.0708.004.

Prussia, G. E., Anderson, J. S., \& Manz, C. C. (1998). Self-leadership and performance outcomes The mediating influence of self-efficacy. Journal of Organizational Behavior, 538(August 1995), 523-538.

Robu, M. (2013). The Dynamics and Importance of SMEs in Economy: The USV Annals of Economics and Public Administration. Volume 13, Issue 1(17),

Ryan, R. M., \& Deci, E. L. (2000b), 'Self-determination theory and the facilitation of intrinsic motivation, social development, and well-being', American Psychologist, vol. 55, no. 1, pp. 68-78.

Ryan, R. M., \& Deci, E. L. (2019). Supporting autonomy, competence, and relatedness: The coaching process from a self-determination theory perspective. In P. Brownell, S. English, \& J. Sabatine (Eds.), Professional coaching: Principles and practice (pp. 231246). New York, NY: Springer. 
Sesen, H., Tabak, A., \& Arlı, O. (2016). Consequences of Self-Leadership: A Study on Primary School Teachers. Educational Sciences: Theory \& Practice. 17. 10.12738/estp.2017.3.0520

Shad, F. S., Sharbiyani, A. A. A., and Abzari, M. (2015), Studying the relationship between selfleadership with job satisfaction and performance improvement. Global Journal of Human Resource Management, Vol. 3, No. 3, pp. 39-57.

Shek, D. T., Ma, C. M., Liu, T. T., \& Siu, A. M. (2015). The role of self-leadership in service leadership. International Journal on Disability and Human Development, 14, 343 - 350.

Singh, R., Kumar, N., \& Puri, S., (2017). Thought self-leadership strategies and sales performance: Integrating selling skills and adaptive selling behavior as missing links. Journal of Business \& Industrial marketing. 32(5), 652-663.

SMEDAN. (2013). SMEDAN and national bureau of statistics collaborative survey: Selected Nigeria's SMEs: Mitigating the Challenges by Gumel, B. I. 29 findings 2013. Abuja: National Bureau of Statistics. Retrieved from http://nigerianstat.gov.ng.

Stewart, G. L., Courtright, S. H., \& Manz, C. C. (2011). Self-leadership: A multilevel review. Journal of Management, 37(1), 185-222

Sweet, S. N., Fortier, M. N., and Strachan S. M., (2012). Testing and Integrating SelfDetermination Theory and Self-Efficacy.

Sydanmaanlakka, P. (2006). Älykäs itsensä johtaminen Talentum. Helsinki.

Uchehara, C. C. (2017). Ex-raying operations of small medium scale enterprises (SMEs) in Nigeria business environment: The challenges. European Journal of Economic and Financial Research, 2(1), 1-20. doi: 10.5281/zenodo.255799.

Van den Broeck, A., Vansteenkiste, M., De Witte, H., Soenens, B., \& Lens, W. (2010). Capturing autonomy, competence and relatedness at work: construction and initial validation of thework-related basic need satisfaction scale. Journal of Occupational and Organizational Psychology, 83(4), 981-1002

Van Zyl, E. (2014). The role of self-leadership in becoming an ethical leader in the South African working context. African Journal of Business Ethics, 8(2), 5-14.

Ward, E., and Eagle, B. (2018). A HEXACO Personality Structure Analysis of Self-Leadership. International Journal of Business and Applied Social Science (IJBASS) https://ijbassnet.com/

Voca, Z., \& Havolli, Y. (2019). The Impact of Human Resources Development on Small and Medium Enterprises (SMEs) Performance. Journal of Economics and Management Sciences. 2. p45. 10.30560/jems. v2n2p45.

Wang, Y., Xie, G., \& Cui, X. (2016). Effect of emotional intelligence and self-leadership on students' coping with stress. Social Behavior and Personality, 44(5), 853-864. doi:10,2224/sbp.2016.44.5.853. 